\title{
Power Device Thermal Fault Tolerant Control of High-Power Three-Level Explosion-Proof Inverter Based on Holographic Equivalent Dual-Mode Modulation
}

\author{
Shi-Zhou Xu, Chun-jie Wang, and Yu-feng Peng \\ College of Electronic and Electrical Engineering, Henan Normal University, Xinxiang, China \\ Correspondence should be addressed to Shi-Zhou Xu; xushizhousiee@163.com
}

Received 6 May 2017; Revised 2 August 2017; Accepted 13 August 2017; Published 2 October 2017

Academic Editor: Michele Riccio

Copyright (C) 2017 Shi-Zhou Xu et al. This is an open access article distributed under the Creative Commons Attribution License, which permits unrestricted use, distribution, and reproduction in any medium, provided the original work is properly cited.

It is necessary for three-level explosion-proof inverters to have high thermal stability and good output characteristics avoiding problems caused by power devices, such as IGBT, so it becomes a hot and difficult research point using only one control algorithm to guarantee both output characteristics and high thermal stability. Firstly, the simplified SVPWM (Space Vector Pulse Width Modulation) algorithm was illustrated based on the NPC (neutral-point-clamped) three-level inverter, and then the quasi-square wave control was brought in and made into a novel holographic equivalent dual-mode modulation algorithm together with the simplified SVPWM. The holographic equivalent model was established to analyze the relative advantages comparing with the two single algorithms. Finally, the dynamic output and steady power device losses were analyzed, based on which the power loss calculation and system simulation were conducted as well. The experiment proved that the high-power three-level explosion-proof inverter has good output characteristics and thermal stability.

\section{Introduction}

The high-power three-level inverter has been applied widely in the field of mine hoist, and it shows high performance in application. However, with the diversification and complexity of applications, inverters used in explosion-proof environments need increasingly high requirements of system stability. There are many factors, like internal faults, overload, transients, and so on, that affect the system stability. But for explosion-proof inverters, feedback from the applications of this stage shows that the primary factor affecting the stability of the system is the thermal fault; that is, the power loss of power device is too large, and the cooling system with certain cooling capacity can not meet the cooling needs and results in damage of power devices due to accumulated heat. Fault tolerant control for thermal fault of inverters has received attention paid by scholars at home and abroad, and some progress has been made already.

The power losses of internal power devices during operation are the main heat sources of inverters. So the modeling analysis of power devices is the major research of thermal analysis, and the topology is shown in Figure 1.

The three-level NPC inverter compared with traditional two-level topology achieves higher transfer density of energy and lower harmonic content of voltage and current. It has been widely used in the field of high-voltage power inverter and now is the main topology of power circuit in the mainstream products from many world-renowned electric manufacturers at this stage, and, therefore, the thermal fault tolerant control based on high-power explosion-proof NPC three-level inverter is the main content of this paper. Several experts and scholars have conducted research in this area with some practical results. Power loss, heat models, and life prediction of power devices were researched in [1] based on three-level NPC inverter, but the thermal models mentioned in the paper are from the datasheets, and the RC equivalent circuit is established accordingly, which causes larger calculation error. The power loss and thermal models were established in [2] based on the platform of ANPC converter and the study of IGBT-Diode encapsulation module, and 


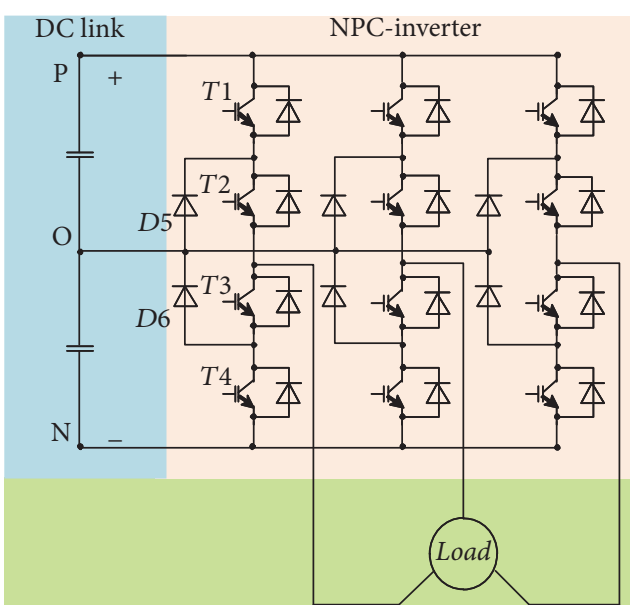

FIGURE 1: Topology of neutral-point-clamped three-level inverter.

meanwhile, the steady-state thermal models were analyzed under air cooling conditions. In [3], the authors analyzed the thermal stress of IGBT module based on traditional PSCAD/ETMDC internal models and achieved the thermal models in consistence with electrical simulation modes, but the mode established by this method has a large calculation error. As the heat source, power losses of power devices have an effect on the inverter thermal field, which has attracted much attention from experts and scholars. A thermal management method of NPC three-level inverter based on IGCT has been proposed in [4], and failover design is also realized by applying appropriate heat management method of power semiconductor devices considering the possibility of protection strategy failure. With respect to loss distribution and junction temperature of power devices, several sets of MW wind power converter are analyzed under different wind speed scales and parameters [5], and it is claimed that thermal stress of inverter power devices in machine side of DFIG is greater than the grid-side (PMSM) converter's. However, the objects are two-level converters. As for the low voltage ride through (LVRT) operating condition, a novel space vector modulation method based on NPC wind power converter to reallocate the loss during failure is proposed in [6], which reorientates heat load of the power devices and equally splits heat generated during the fault process to reduce the junction temperature of power devices. In [7], the temperature management of $\mathrm{H}$-bridge inverter based on dual-mode control is developed, and the strategy combined quasi-square wave modulation with PWM modulation, with which the power loss can be reduced by $20 \%$ to $50 \%$. Thermal analysis has been conducted in various topologies and applications, and temperature management is especially virtual in engineering application. High-power three-level explosion-proof inverters are more sensitive to temperature, when working in terrible underground coal mine, and therefore, an effective control method considering power quality and thermal stability of inverters equally during operation is imperative. Heat-pipe and water-cooling heat dissipation methods for high-power explosion-proof inverters have been used widely at this stage. And fault tolerant capability of the

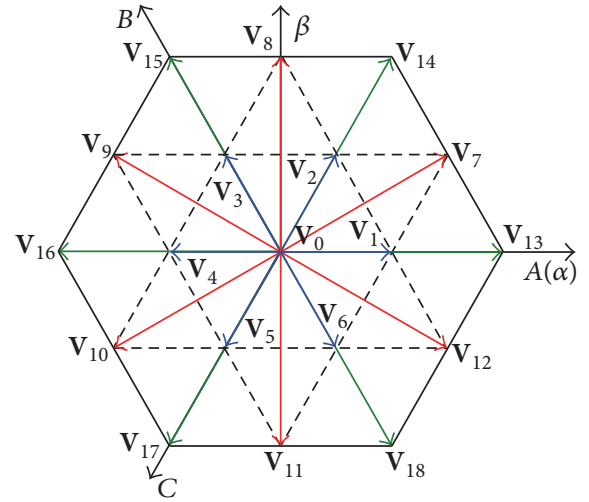

FIGURE 2: Space voltage vector diagram of three- level inverter.

heatsink is needed to meet the demand of heat tolerance. But it is difficult to increase redundancy of cooling systems due to the limited space under explosion-proof conditions.

Hence, considering modulation strategy, a new modulation algorithm based on holographic equivalent dual mode is proposed in this paper. The calculation can not only adjust dynamic power device losses according to output property, but also achieve optimal thermal management of power devices in different speed zones of hoister. Therefore, heat fault tolerant control for high-power three-level explosionproof inverter can be realized.

\section{Modulation Principle of Holographic Equivalent Dual Mode}

Firstly, the principle of SVPWM is introduced simply based on the inverter topology shown in Figure 1. As can be seen in Figure 1 each bridge arm is composed of four anti-parallel diodes $S_{x y}(x=a, b, c ; y=1,2,3,4)$ and two clamping diodes $D_{x y}(x=a, b, c ; y=1,2)$, respectively. As clamping diodes, each phase outputs $\mathrm{P}, \mathrm{O}$, and $\mathrm{N}$ three levels, whose voltages are $+U_{\mathrm{dc}} / 2,0$ and $-U_{\mathrm{dc}} / 2$, respectively. Through combining three-phase output voltages and 27 kinds of space voltage vectors are obtained as shown in Figure 2 [8]. The general equation of space voltage vector is shown as follows:

$$
\mathbf{V}=\frac{U_{\mathrm{dc}}}{3}\left(S_{a}+S_{b} e^{j 2 \pi / 3}+S_{c} e^{j 4 \pi / 3}\right),
$$

where $S_{a}, S_{b}$, and $S_{c}$ represent the state of phases A, B, and C respectively.

The space voltage vectors depicted in Figure 2 can be divided into four types: zero vector $\mathbf{V}_{0}$, small vectors $\mathbf{V}_{1}-\mathbf{V}_{6}$, medium vectors $\mathbf{V}_{7}-\mathbf{V}_{12}$, and long vectors $\mathbf{V}_{13}-\mathbf{V}_{18}$. Table 1 lists the space voltage vectors corresponding to the output voltage states.

The diagram of three-level voltage space vectors shown in Figure 2 is resolved to stacked six two-level space vector diagrams, as shown in Figure 3, which are marked by $S=1 \sim$ 6.

Due to the symmetry of the six small hexagons, the algorithm of SVPWM is analyzed based on reference voltage vector through the small hexagon marked with $S=1$. As 


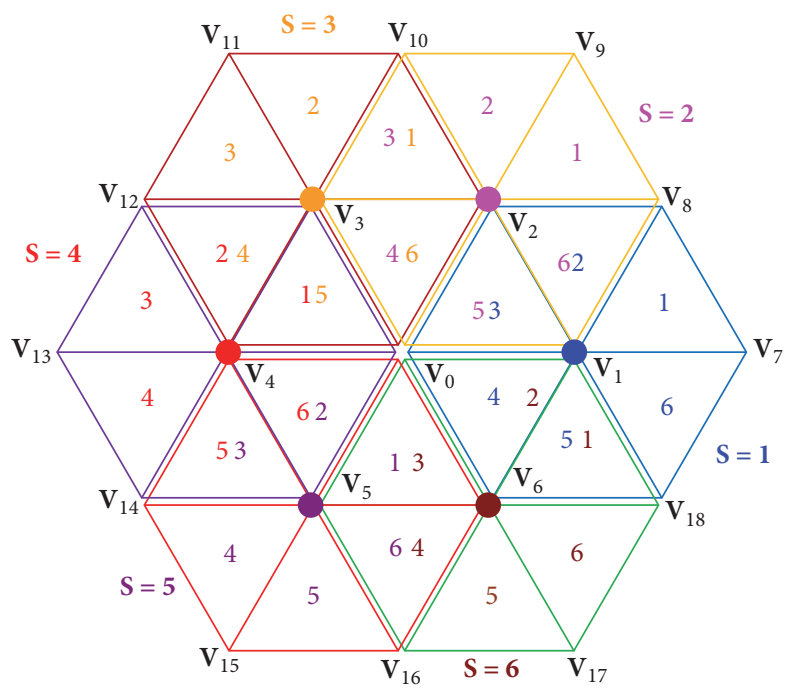

FIGURE 3: Diagram of transforming between three-level space vector to two-level space vector.

TABLE 1: Space voltage sectors and corresponding output voltage states.

\begin{tabular}{lc}
\hline Space voltage vectors & Output voltage state \\
\hline $\mathbf{V}_{0}$ & PPP, OOO, NNN \\
$\mathbf{V}_{1}$ & POO, ONN \\
$\mathbf{V}_{2}$ & PPO, OON \\
$\mathbf{V}_{3}$ & OPO, NON \\
$\mathbf{V}_{4}$ & OPP, NOO \\
$\mathbf{V}_{5}$ & OOP, NNO \\
$\mathbf{V}_{6}$ & POP, ONO \\
$\mathbf{V}_{7}$ & PON \\
$\mathbf{V}_{8}$ & OPN \\
$\mathbf{V}_{9}$ & NPO \\
$\mathbf{V}_{10}$ & NOP \\
$\mathbf{V}_{11}$ & ONP \\
$\mathbf{V}_{12}$ & PNO \\
$\mathbf{V}_{13}$ & PNN \\
$\mathbf{V}_{14}$ & PPN \\
$\mathbf{V}_{15}$ & NPN \\
$\mathbf{V}_{16}$ & NPP \\
$\mathbf{V}_{17}$ & NNP \\
$\mathbf{V}_{18}$ & PNP \\
\hline
\end{tabular}

shown in Figure 4, the two-level space vector is divided into six triangular sectors, as reference voltage vector $V_{\text {ref }}$ located in the first triangular sector, and, according to vectorial resultant rule, the basic vectors $V_{1}, V_{7}$, and $V_{13}$ result in $V_{\text {ref }}$. Vector translation of reference voltages under different $S$ values is shown in Table 2 .

Based on the principle of volt-second balance, the relationship can be expressed as follows:

$$
\begin{aligned}
\mathbf{V}_{\text {ref }} T_{s} & =\mathbf{V}_{1} T_{1}+\mathbf{V}_{13} T_{13}+\mathbf{V}_{7} T_{7} \\
T_{s} & =T_{1}+T_{13}+T_{7},
\end{aligned}
$$

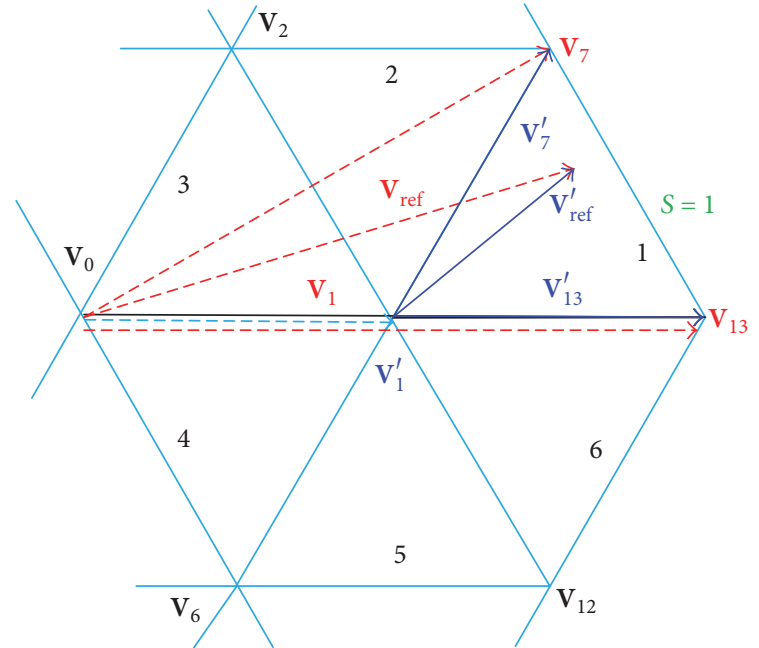

FIGURE 4: Vector translation of reference voltage under $S=1$.

where $\mathbf{V}_{\text {ref }}$ is the reference voltage vector, $T_{s}$ is the carrier cycle, and $T_{1}, T_{13}$, and $T_{7}$ are effecting time, respectively.

Introducing translation vector $\mathbf{V}_{1}$, so

$$
\begin{aligned}
\left(\mathbf{V}_{\text {ref }}-\mathbf{V}_{1}\right) \cdot T_{s}= & \left(\mathbf{V}_{1}-\mathbf{V}_{1}\right) \cdot T_{1}+\left(\mathbf{V}_{13}-\mathbf{V}_{1}\right) \cdot T_{13} \\
& +\left(\mathbf{V}_{7}-\mathbf{V}_{1}\right) \cdot T_{7}
\end{aligned}
$$

On the basis of Figure 4, it can be expressed as follows:

$$
\mathbf{V}_{\mathrm{ref}}^{\prime} \cdot T_{s}=\mathbf{V}_{1}^{\prime} \cdot T_{1}+\mathbf{V}_{13}^{\prime} \cdot T_{13}+\mathbf{V}_{7}^{\prime} \cdot T_{7},
$$

where $\mathbf{V}_{\text {ref }}^{\prime}, \mathbf{V}_{1}^{\prime}, \mathbf{V}_{13}^{\prime}$, and $\mathbf{V}_{7}^{\prime}$ are the shifted voltage space vectors.

As shown in Figure 4, after the shift of voltage, voltage vector $\mathbf{V}_{1}^{\prime}$ becomes the origin of the two-level space vector diagram, which is known as zero vector. $\mathbf{V}_{13}^{\prime}$ and $\mathbf{V}_{7}^{\prime}$ are the basic vectors. 


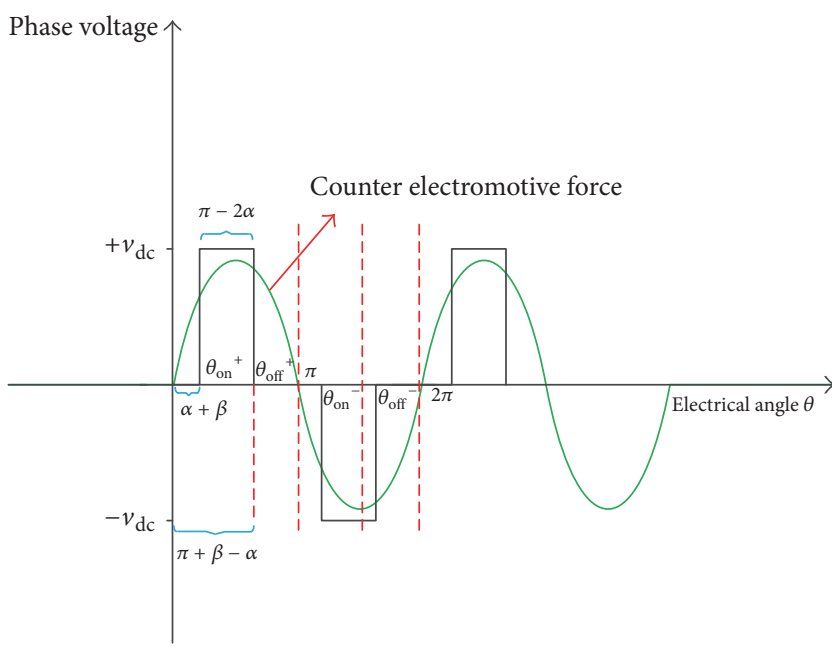

Figure 5: Quasi-square-wave voltage and counter electromotive force corresponding to the angle of the basic waveform and turn-off position.

Through the above analysis, it can be found out that the first step is to judge the reference voltage vector, located in two-level space vector label $S$, according to Figures 2 and 3 ; then according to Table 2, depending on the value of different $S$, shift the reference voltage vector correspondingly. Finally, effecting time of basic vector can be calculated and the switching sequence of power devices can be determined as well [9-13].

In Table $2, V_{\alpha \_ \text {ref }}, V_{\beta \text { ref }}$ are the reference voltages of space vectors, which are the two basic components of coordinate. $V_{\alpha \_ \text {ref }}^{\prime}, V_{\beta_{\text {ref }}}^{\prime}$ are their corresponding translation voltages.

Fault tolerant control of thermal stability based on holographic equivalent dual mode is a method to switch two holographic equivalent modes to adjust the losses of power devices. The first mode, improved on the basis of traditional PWM modulation, is a simplified SVPWM algorithm based on three-level reference voltage vector transformation. This algorithm can simplify the three-level power device control, reduce the computation time, and improve the quality of the output power quality. But the power loss under this modulation is too large to maintain the thermal stability under continuous working. The second mode is quasi-square wave modulation algorithm, which needs the quasi-square wave voltage in each cycle to switch the power devices on and off twice. As shown in Figure 5, compared with the simplified SVPWM, this algorithm has a much lower power loss of power devices and generates much less heat during operation process. However, the output power quality is much worse and cannot be suitable for some operation conditions asking for high performance control effect. These two kinds of modulation act as the two holographic equivalent modes. In the different periods of hoist, according to the performance requirement of the control motor and different temperature control of power devices, the modulation will be switched between the two modes, which will keep balance between outputting high quality power to ensure the excellent ascension performance of hoist, and reducing power loss of

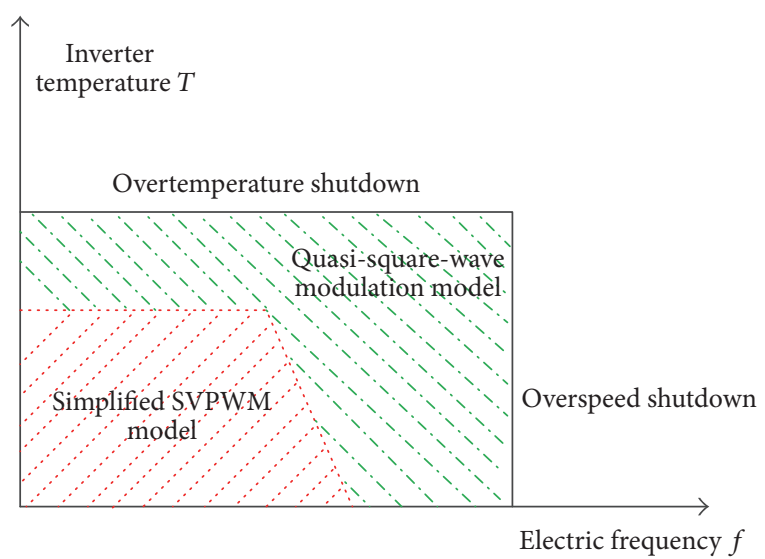

FIgURE 6: Temperature-frequency regional distribution with runtime of dual-mode modulation.

power devices. On the basis of modulation switching, the thermal stability fault tolerant control during transient failure of cooling system can be realized. The operation time and temperature-frequency regional distribution of dual-mode modulation are shown in Figure 6.

Two kinds of modulation mechanisms of the holographic equivalent modes are as follows:

(1) The simplified SVPWM is based on vector translation of three-level reference voltage: in simplified SVPWM mode, the direct relationship between input voltage command and PWM duty ratio is

$$
d(t)=\frac{v(t)}{v_{\mathrm{dc}}}
$$

(2) Quasi-square-wave modulation: in quasi-squarewave modulation mode, the relationships between switchon and -off angles and orthogonal and direct harmonic components are as follows:

$$
\begin{aligned}
& v_{n, q}=\left(\frac{4 v_{\mathrm{dc}}}{n \pi}\right) \cos (n \alpha) \cos (n \beta), \\
& v_{n, d}=\left(\frac{4 v_{\mathrm{dc}}}{n \pi}\right) \cos (n \alpha) \sin (n \beta) .
\end{aligned}
$$

Benchmark effective power/torque and reactive power are decided by the value of $\alpha$ and $\beta$. Both of them have relationships with reference voltage components as follows:

$$
\begin{aligned}
& \alpha=\left(\frac{\pi}{4 v_{\mathrm{dc}}}\right) \cos ^{-1} \sqrt{\left(v_{1 q}^{2}+v_{1 d}^{2}\right)}, \\
& \beta=\tan ^{-1}\left(\frac{v_{1 d}}{v_{1 q}}\right) .
\end{aligned}
$$

\section{Simulation and Experiment}

The experiment platform is shown in Figure 7, including motor part and inverter part [14-17].

The parameters of winding asynchronous motor and component parameters of inverter main circuit are shown in Tables 3 and 4, respectively. 
TABLE 2: Vector translations of reference voltages under different $S$ values.

\begin{tabular}{|c|c|c|}
\hline$S$ & $V_{\alpha \_ \text {ref }}^{\prime}$ & $V_{\beta \text { ref }}^{\prime}$ \\
\hline 1 & $V_{\alpha_{-} \text {ref }}-\frac{u_{\mathrm{dc}}}{3}$ & $V_{\beta_{-} \text {ref }}$ \\
\hline 2 & $V_{\alpha_{-} \text {ref }}-\frac{u_{\mathrm{dc}}}{6}$ & $V_{\beta \_ \text {ref }}-\frac{u_{\mathrm{dc}}}{2 \sqrt{3}}$ \\
\hline 3 & $V_{\alpha_{-} \text {ref }}+\frac{u_{\mathrm{dc}}}{6}$ & $V_{\beta_{\text {_ref }}}-\frac{u_{\mathrm{dc}}}{2}$ \\
\hline 4 & $V_{\alpha \_ \text {ref }}+\frac{u_{\mathrm{dc}}}{3}$ & $V_{\beta \text { ref }}$ \\
\hline 5 & $V_{\alpha \_ \text {ref }}+\frac{u_{\mathrm{dc}}}{6}$ & $V_{\beta \text { ref }}+\frac{u_{\mathrm{dc}}}{2 \sqrt{3}}$ \\
\hline 6 & $V_{\alpha \_ \text {ref }}-\frac{u_{\mathrm{dc}}}{6}$ & $V_{\beta \text { ref }}+\frac{u_{\mathrm{dc}}}{2 \sqrt{3}}$ \\
\hline
\end{tabular}

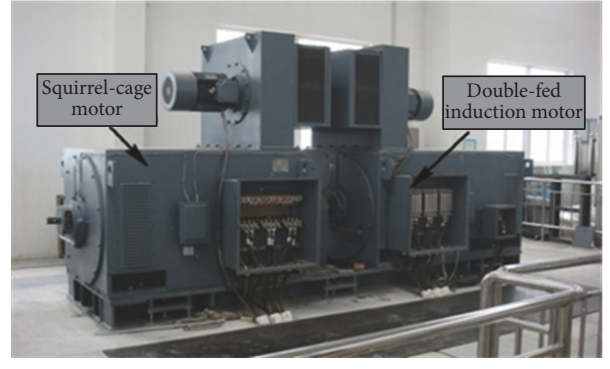

(a)

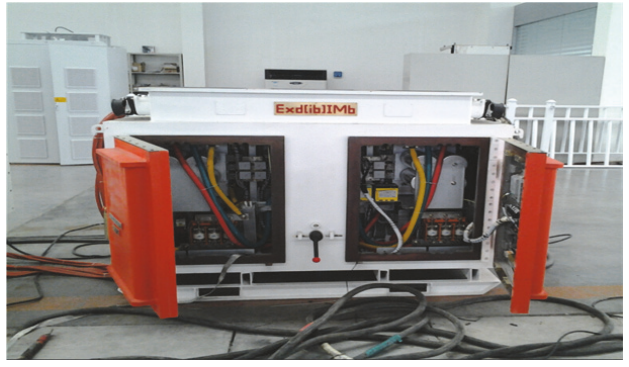

(b)

FIGURE 7: Experiment platform. (a) Motor part; (b) inverter part.

TABLE 3: Parameters of winding asynchronous motor.

\begin{tabular}{lc}
\hline Rated power $P_{d}(\mathrm{~kW})$ & 475 \\
Stator voltage $U_{s}(\mathrm{~V})$ & 6000 \\
Stator current $I_{d}(\mathrm{~A})$ & 59 \\
Rotor voltage $U_{r}(\mathrm{~V})$ & 640 \\
Rotor current $I_{r}(\mathrm{~A})$ & 435 \\
Rated speed $(\mathrm{r} / \mathrm{min})$ & 735 \\
Power factor & 0.85 \\
\hline
\end{tabular}

TABLE 4: Component parameters of inverter main circuit.

\begin{tabular}{lc}
\hline$U_{\mathrm{dc}}$ & $1100 \mathrm{~V}$ \\
DC-link capacitor & $1800 \mu \mathrm{F} / 1300 \mathrm{~V}$ \\
Power device parameters & Infineon, FF1400R17IE4 \\
Switching frequency & $2000 \mathrm{~Hz}$ \\
\hline
\end{tabular}

The well depth is $348 \mathrm{~m}$. Meanwhile, the lifting conditions of one cycle are shown in Figure 8.

Simulation analysis of power losses in the same bridge $T 1$ and its anti-parallel diode in NPC three-level explosion-proof inverter, based on two kinds of holographic equivalent mode, can be obtained in accordance with [14-17]. The simulation results are as shown in Figure 9.

It can be seen by analyzing the simulation results in Figures 9(a)-9(d) that power losses of $T 1$ and its antiparallel diode, based on simplified SVPWM mode, are much larger than the ones under quasi-square-wave modulation. In Figure 9(e), the power losses curves of power devices under dual-mode modulation were figured out. What is more, T0 in Figure 9(e) is the switching point between quasisquare-wave modulation and simplified SVPWM, and the quasi-square-wave modulation was used firstly at the start stage to reduce the power losses in case of overtemperature caused by high voltage and large current during overload period. Put the power loss values in Figure 9 into highpower explosion-proof inverter mode as heat sources, and the thermal simulation can be obtained in Figure 8.

Through the thermal analysis in Figure 10 based on two kinds of holographic equivalent modes, it can be found out that, in inverter system, temperature rises of heatsink and substrate using quasi-square-wave modulation mode have an average advantage over using simplified SVPWM mode by appropriate $15^{\circ} \mathrm{C}$.

The electrical performance of the three-level explosionproof inverter under normal condition in one cycle is shown in Figure 11, in which the mode switching point is the time $T 0$. It can be seen from the Figure 11 that the inverter has not very good output properties during quasi-square-wave modulation compared with simplified SVPWM, because the torque current has a much higher harmonic content and it will bring pulse vibration into the motor. As shown in Figure 12, the harmonic characteristic based on the simplified SVPWM is a little better than the one based on the dualmode modulation. But both of them have an acceptable harmonic performance and in this high-power application 


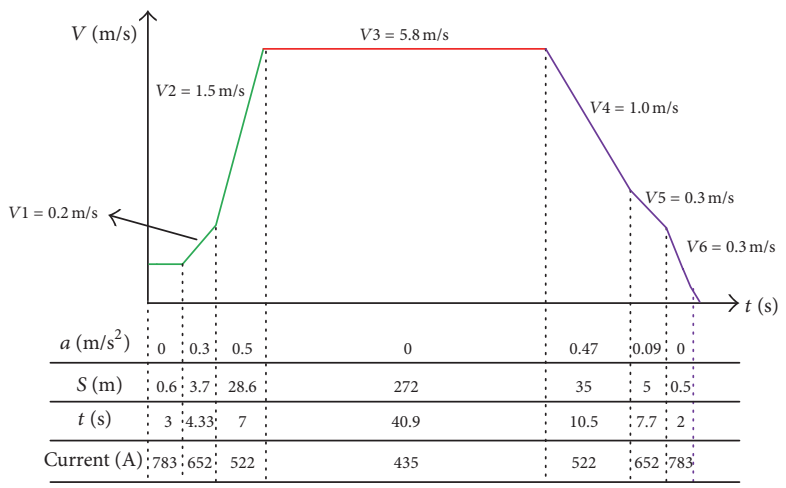

FIGURE 8: Lifting conditions of mine hoist in one cycle.

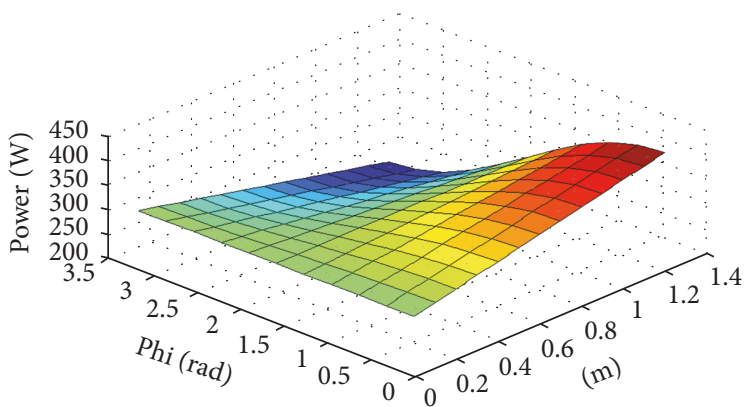

(a)

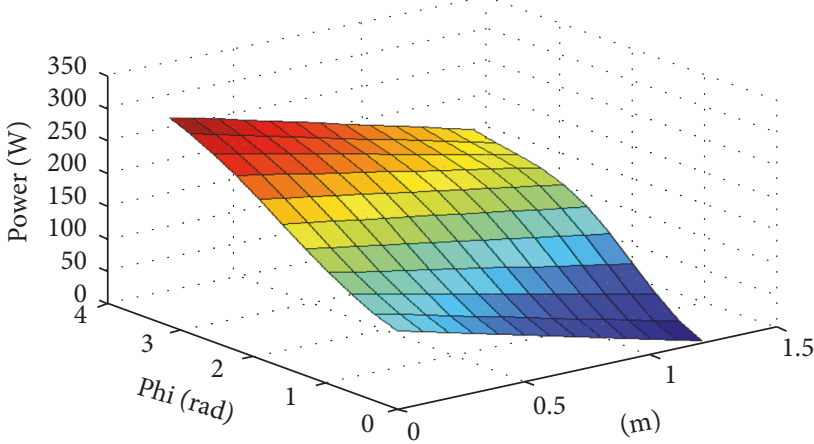

(c)

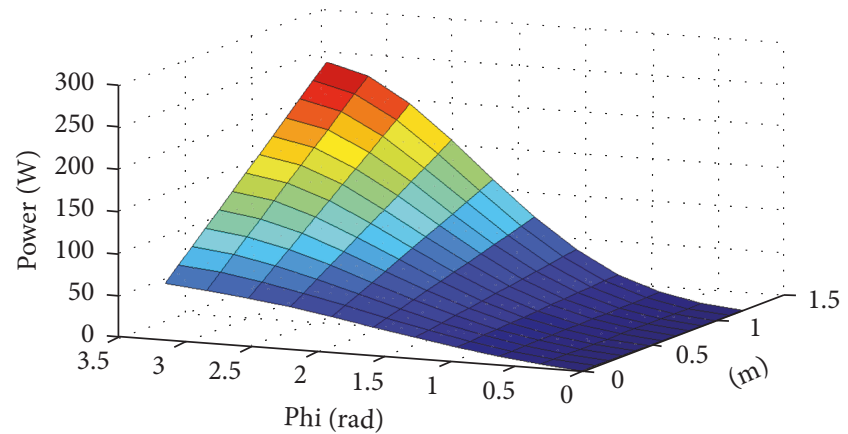

(b)

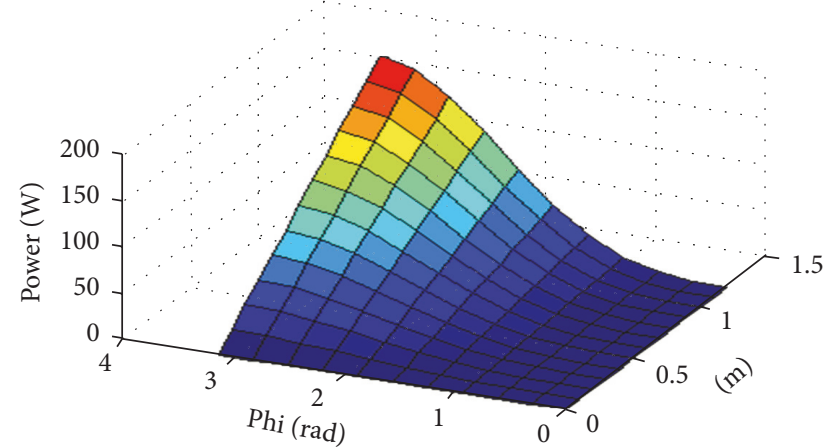

(d)

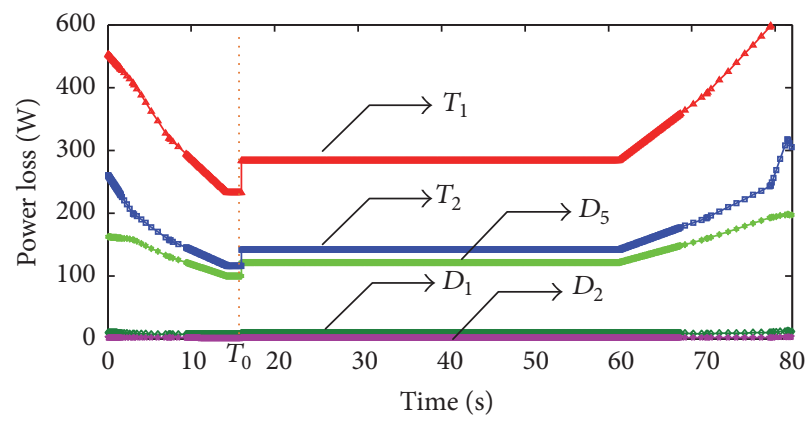

(e)

FIGURE 9: Power loss comparison between two equivalent modes. (a) Power loss of T1 based on simplified SVPWM; (b) power loss of T1 based on quasi-square-wave modulation; (c) power loss of diode based on simplified SVPWM; (d) power loss of diode based on quasi-square-wave modulation; (e) power loss curves of power devices under dual-mode modulation. 


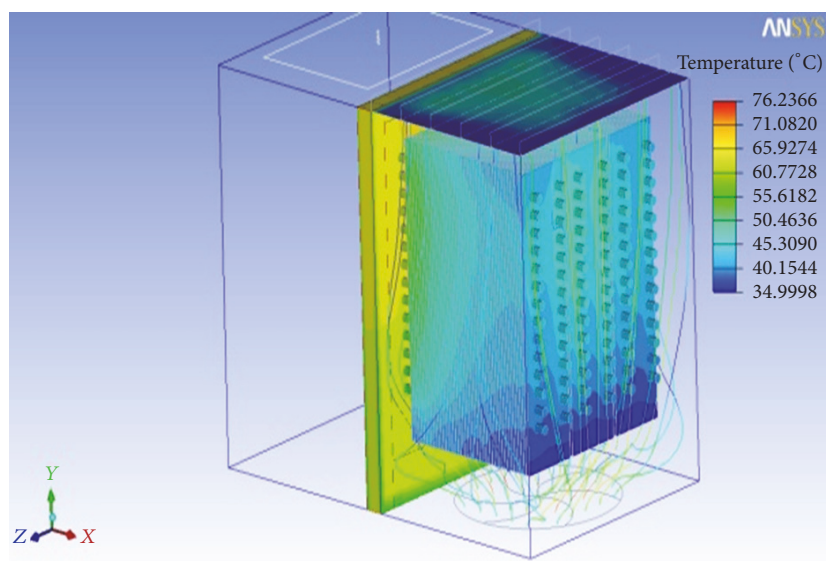

(a)

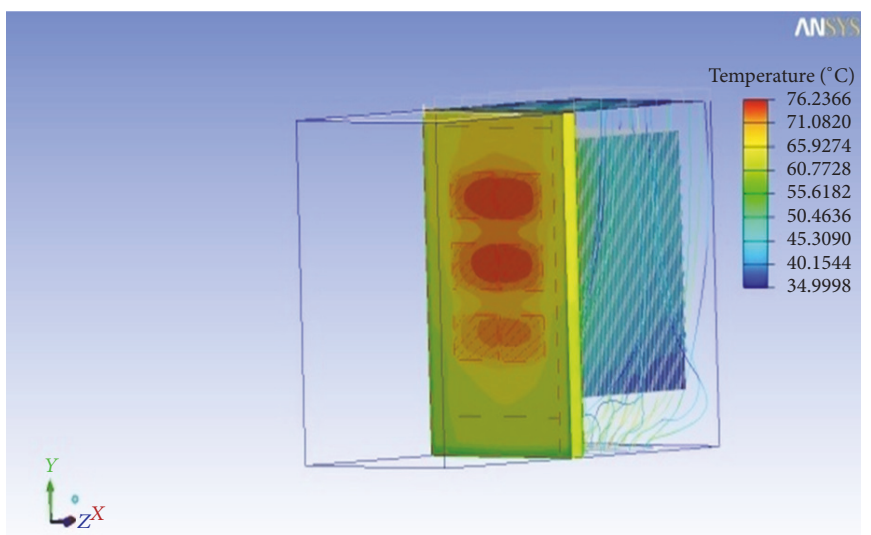

(c)

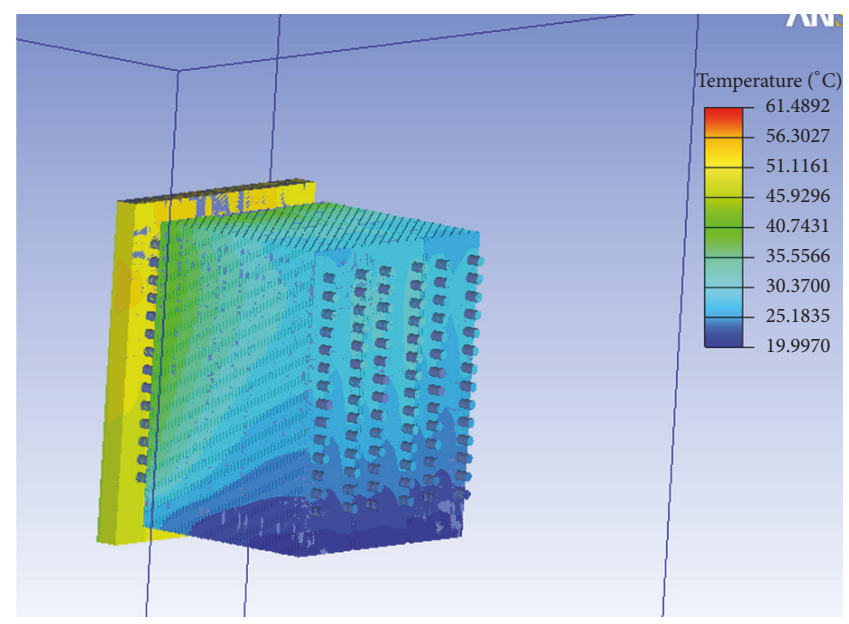

(b)

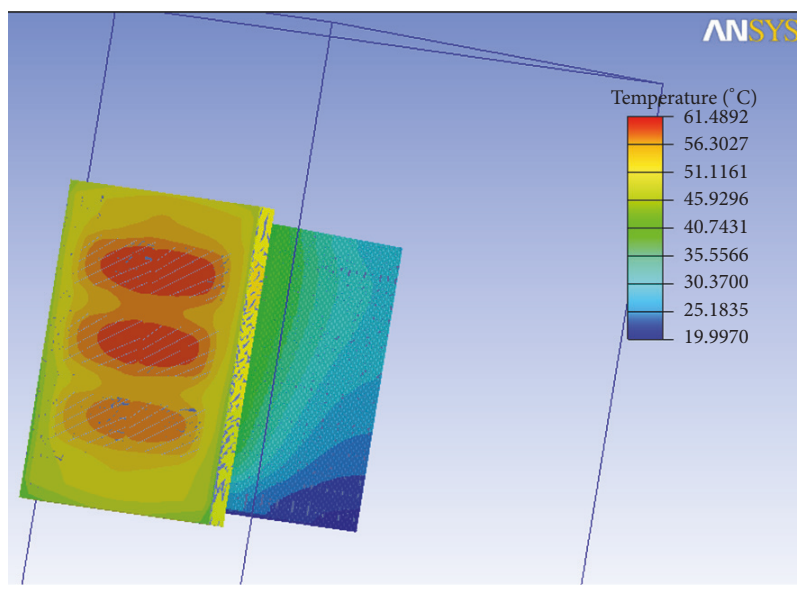

(d)

FIGURE 10: Thermal analysis comparison between the two equivalent modes. (a) Temperature rise of heatsink based on simplified SVPWM; (b) temperature rise of heatsink based on quasi-square-wave modulation; (c) temperature rise of substrate based on simplified SVPWM; (d) temperature rise of substrate based on quasi-square-wave modulation.

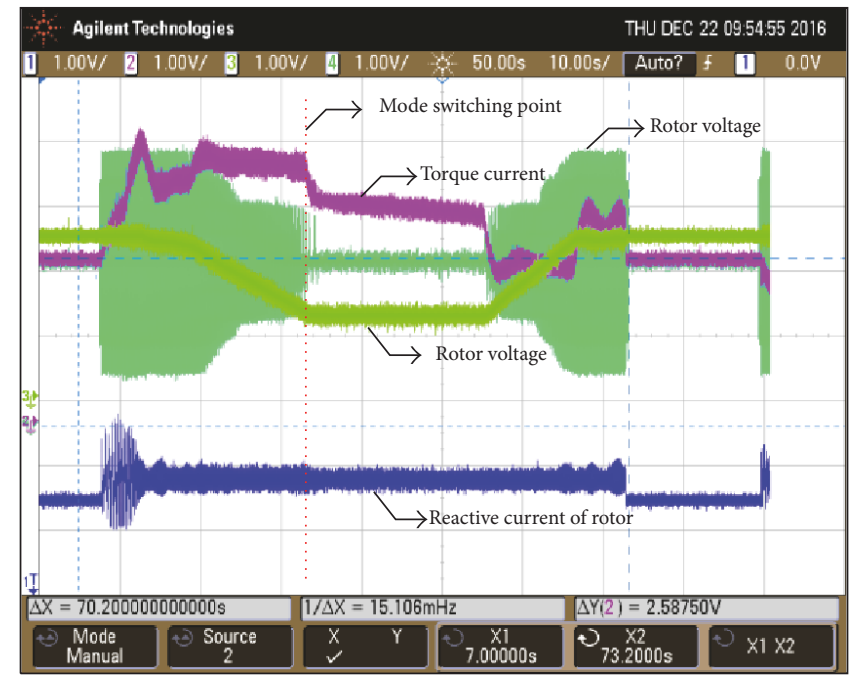

FIGURE 11: Electrical performance of inverter. 


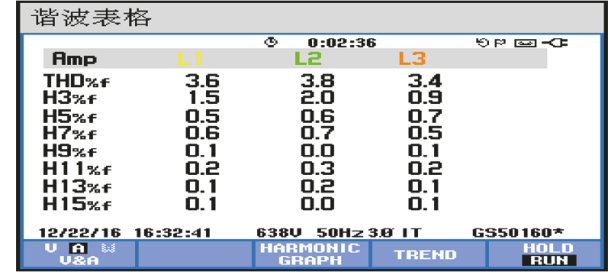

(a) Harmonic characteristic based on simplified SVPWM

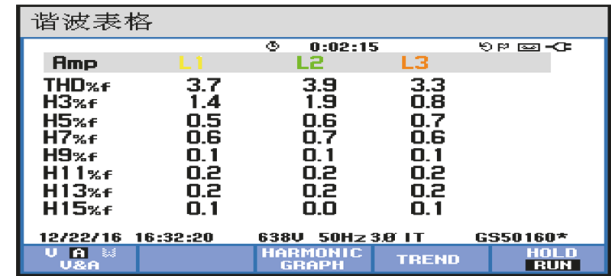

(b) Harmonic characteristic based on dual-mode modulation

FIGURE 12: Harmonic characteristic comparison.

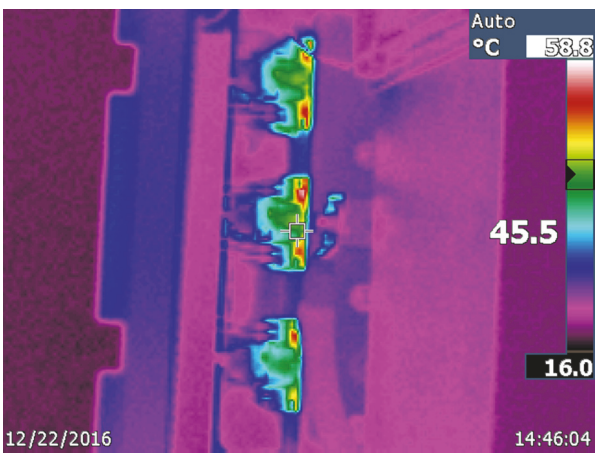

(a)

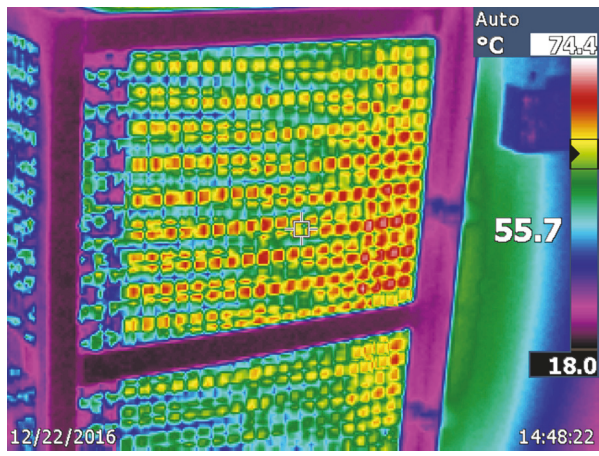

(c)

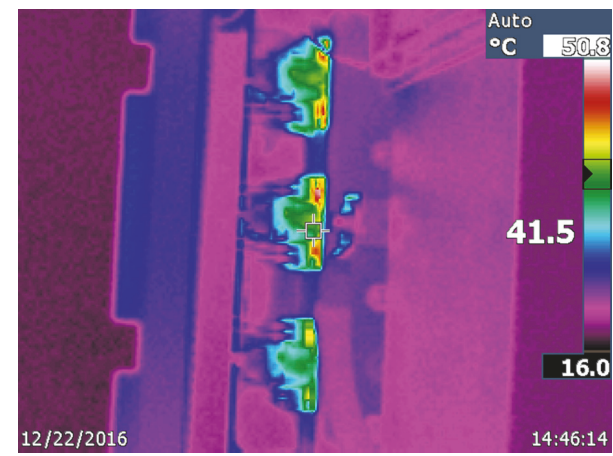

(b)

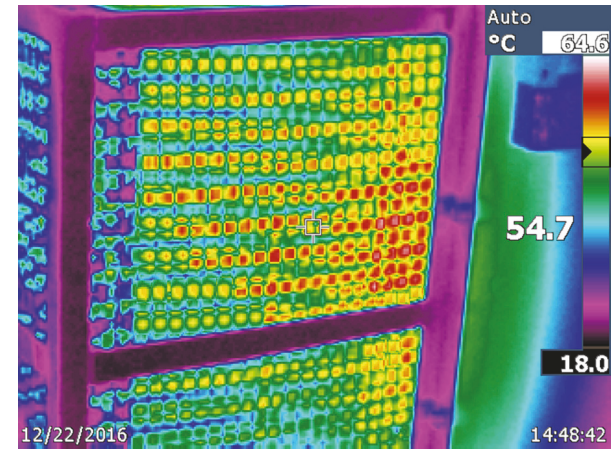

(d)

FIGURE 13: Surface and the substrate temperature rises of IGBT based on holographic equivalent dual mode. (a) Surface temperature rise of IGBT based on simplified SVPWM; (b) surface temperature rise of IGBT based on quasi-square-wave modulation; (c) substrate temperature rise of IGBT based on simplified SVPWM; (d) substrate temperature rise of IGBT based on quasi-square-wave modulation.

they almost are the same. Based on the experimental result comparison of power loss analysis, thermal analysis, and the temperature rise of the same IGBT $T 1$ and its anti-parallel diode in Figure 13, it can be seen that the power loss and temperature rise using simplified SVPWM mode are greater than the ones using quasi-square-wave modulation mode by approximately $9^{\circ} \mathrm{C}$. The thermal stability fault tolerant control based on holographic equivalent dual mode is to use this characteristic in different stages of the hoist's each operation cycle, according to the need of the controlled motor performance and thermal condition. In the start, the motor has a much larger overload and the inverter has a much larger output current as well, which is just stage asking for starting the given mode of quasi-square-wave modulation mode, to reduce the power losses of power devices effectively, maintaining the stability of hoist running all the way. In constant speed stage, with a higher speed, it requires a much smaller motor vibration and a much higher running stability, and then the modulation switches into the simplified SVPWM, which can guarantee the high quality power of inverter output and good running characteristics of motor and also guarantee that the power loss of power devices is still controllable under the inverter cooling system in constant speed period to realize power device thermal fault tolerant control of the whole inverter system.

\section{Conclusion}

Based on high-power three-level explosion-proof inverter output characteristic and the special requirements of thermal 
stability, in this paper, we put forward a holographic equivalent dual-mode control algorithm based on the simplified SVPWM and quasi-square-wave modulation and calculate the power losses of power devices in three-level explosionproof inverter on this basis and establish thermal models of power devices and cooling system for thermal simulation. The effectiveness of holographic equivalent dual-mode control on both the system output characteristics and thermal stability is verified by experimental analysis, so this mode plays an important role in realizing power device thermal fault tolerant control and improving the thermal stability of high-power explosion-proof inverter.

\section{Conflicts of Interest}

The authors declare that there are no conflicts of interest regarding the publication of this article.

\section{Acknowledgments}

The authors would like to thank the Doctoral Scientific Research Start-Up Foundation of Henan Normal University, Grant no. 5101239170001.

\section{References}

[1] Y. Firouz, M. T. Bina, and B. Eskandari, "Efficiency of three-level neutral-point clamped converters: Analysis and experimental validation of power losses, thermal modelling and lifetime prediction," IET Power Electronics, vol. 7, no. 1, pp. 209-219, 2014.

[2] O. S. Senturk, S. Munk-Nielsen, R. Teodorescu, L. Helle, and P. Rodriguez, "Converter structure-based power loss and static thermal modeling of the press-pack igbt-based three-level ANPC and HB VSCs applied to multi-MW wind turbines," in Proceedings of the 2010 2nd IEEE Energy Conversion Congress and Exposition, (ECCE '10), pp. 2778-2785, IEEE, Atlanta, GA, USA, September 2010.

[3] R. Pittini, S. D’Arco, M. Hernes, and A. Petterteig, "Thermal stress analysis of IGBT modules in VSCs for PMSG in large offshore wind energy conversion systems," in Proceedings of the 2011 14th European Conference on Power Electronics and Applications, (EPE '11), pp. 1-10, IEEE, Birmingham, UK, September 2011.

[4] A. V. Rocha, H. De Paula, M. E. Dos Santos, and B. J. Cardoso Filho, "A thermal management approach to faultresilient design of three-level IGCT-based NPC converters," IEEE Transactions on Industry Applications, vol. 49, no. 6, pp. 2684-2691, 2013.

[5] D. Zhou, F. Blaabjerg, M. Lau, and M. Tonnes, “Thermal analysis of multi-MW two-level wind power converter," in Proceedings of the 38th Annual Conference on IEEE Industrial Electronics Society, (IECON '12), pp. 5858-5864, IEEE, Montreal, QC, Canada, October 2012.

[6] K. Ma, F. Blaabjerg, and M. Liserre, "Thermal analysis of multilevel grid side converters for $10 \mathrm{MW}$ wind turbines under low voltage ride through," in Proceedings of the 3rd Annual IEEE Energy Conversion Congress and Exposition, (ECCE '11), pp. 2117-2124, IEEE, Phoenix, AZ, USA, September 2011.

[7] W. U. N. Fernando, L. Papini, and C. Gerada, "Converter temperature regulation with dual mode control of fault-tolerant permanent magnet motors," in Proceedings of the 4th Annual IEEE Energy Conversion Congress and Exposition (ECCE '12), pp. 1902-1908, IEEE, Raleigh, NC, USA, September 2012.

[8] Z.-B. Ye, Key Technology Research of High Power Three-level Double-fed Mine Hoist [Ph.D. dissertation], China University of Mining and Technology, Beijing Shi, China, 2010.

[9] U. R. Prasanna and A. K. Rathore, "Analysis, design, and experimental results of a novel soft-switching snubberless currentfed half-bridge front-end converter-based pv inverter," IEEE Transactions on Power Electronics, vol. 28, no. 7, pp. 3219-3230, 2013.

[10] F. Krismer and J. W. Kolar, "Accurate power loss model derivation of a high-current dual active bridge converter for an automotive application," IEEE Transactions on Industrial Electronics, vol. 57, no. 3, pp. 881-891, 2010.

[11] D. Xu, H. Lu, L. Huang, S. Azuma, M. Kimata, and R. Uchida, "Power loss and junction temperature analysis of power semiconductor devices," IEEE Transactions on Industry Applications, vol. 38, no. 5, pp. 1426-1431, 2002.

[12] S. Bernet, "Recent developments of high power converters for industry and traction applications," IEEE Transactions on Power Electronics, vol. 15, no. 6, pp. 1102-1117, 2000.

[13] Jing W., Study on Power Device Losses of High-Power Three-Level Converter [Ph.D. dissertation], China University of Mining and Technology, Beijing Shi, China, 2010.

[14] S.-Z. Xu, Y.-F. Peng, and S.-Y. Li, "Application thermal research of forced-air cooling system in high-power NPC three-level inverter based on power module block," Case Studies in Thermal Engineering, vol. 8, pp. 387-397, 2016.

[15] S.-Z. Xu and F.-Y. He, "The optimized design of a NPC threelevel inverter forced-air cooling system based on dynamic power-loss calculations of the maximum power-loss range," Journal of Power Electronics, vol. 16, no. 4, pp. 1598-1611, 2016.

[16] F.-Y. He, S.-Z. Xu, and C.-F. Geng, "Improvement on the laminated busbar of NPC three-level inverters based on a supersymmetric mirror circulation 3D cubical thermal model," Journal of Power Electronics, vol. 16, no. 6, Article ID JPE 16-610, pp. 2085-2098, 2016.

[17] N. N. Yang, C. J. Wu, R. Jia, and C. Liu, "Modeling and characteristics analysis for a buck-boost converter in pseudocontinuous conduction mode based on fractional calculus," Mathematical Problems in Engineering, vol. 2016, Article ID 6835910, pp. 1-13, 2016. 


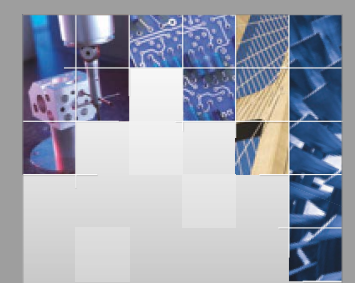

\section{Enfincering}
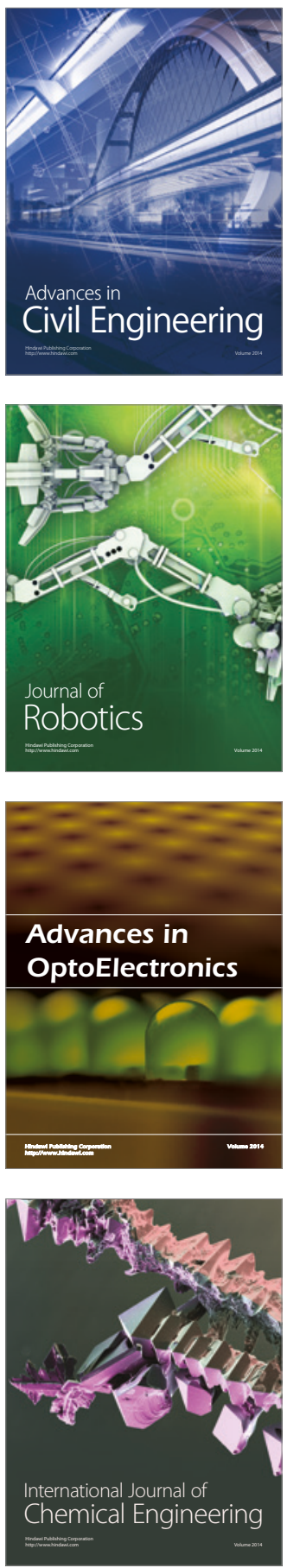

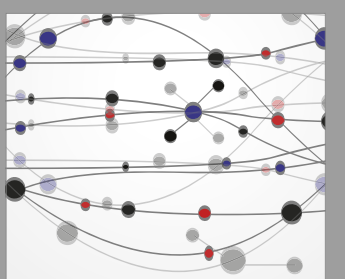

The Scientific World Journal

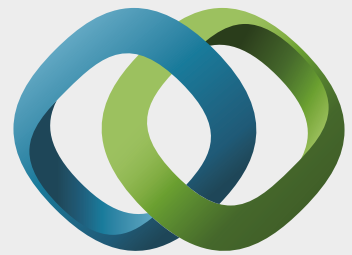

\section{Hindawi}

Submit your manuscripts at

https://www.hindawi.com
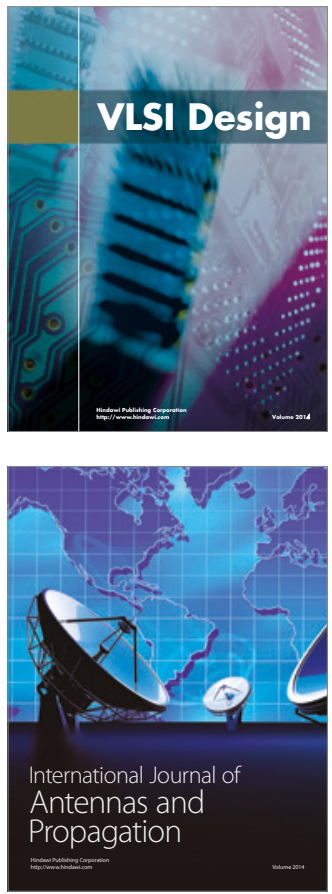

\section{Rotating}

Machinery
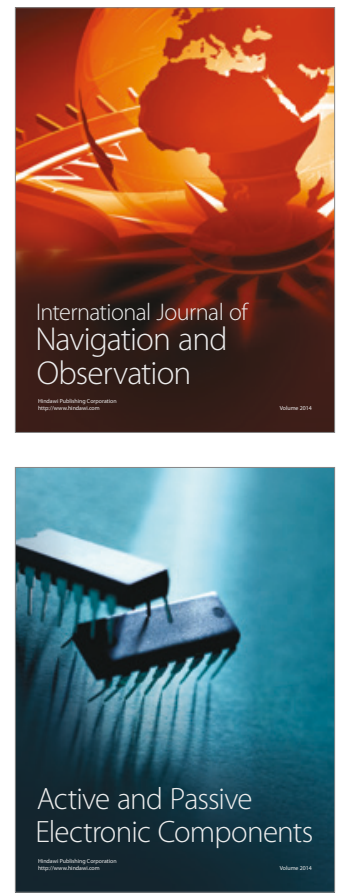
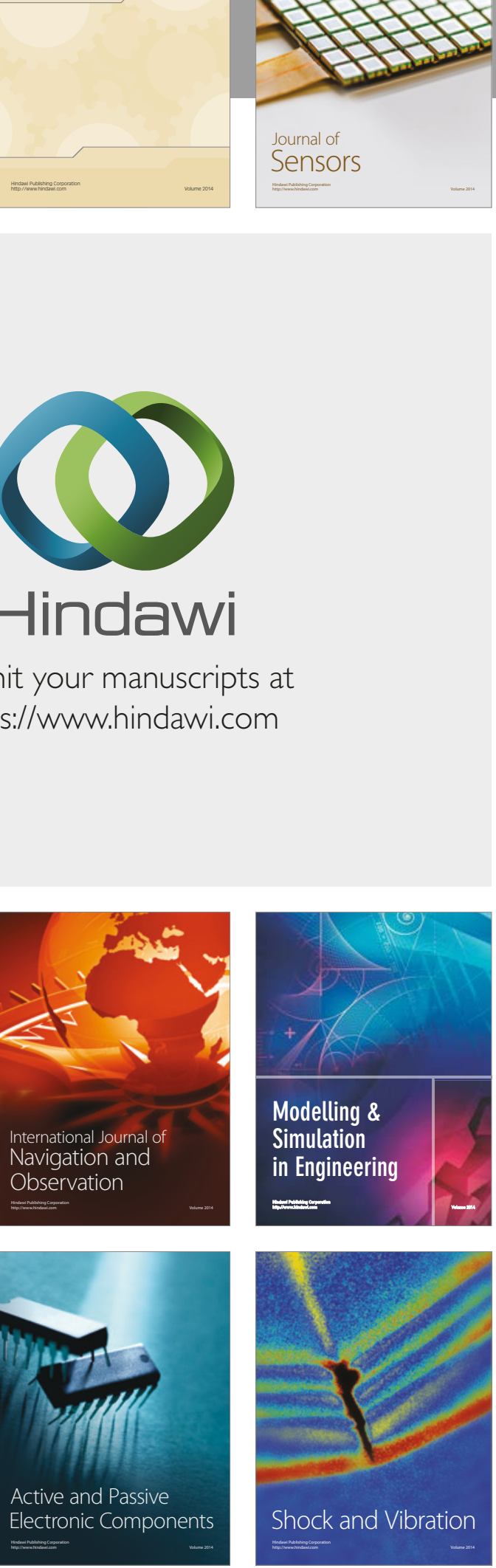
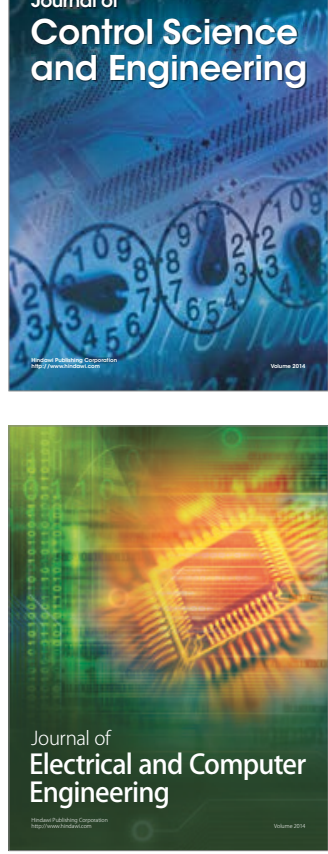

Distributed

Journal of

Control Science

and Engineering
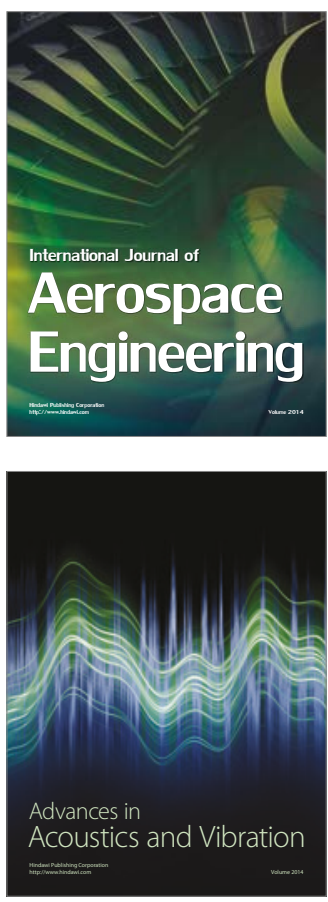

Sensor Networks 